\title{
Synthesis Kinetics of Polymer / Copolymer Latexes via Radical Ring- Opening Emulsion Polymerization of Vinylcyclopropane
}

\author{
P. Sarker ${ }^{1,2}$, J. R. Ebdon ${ }^{1}$, S. Rimmer ${ }^{1}$, M. A. J. Miah, ${ }^{3}$ H. Ahmad ${ }^{3 *}$ \\ ${ }^{1}$ The Polymer and Biomaterials Chemistry Laboratories, Department of Chemistry, University of \\ Sheffield, Sheffield S3 7HF, UK \\ ${ }^{2} 47$ St. Thomas Close, Comberton, Cambridge, CB23 7DN, UK \\ ${ }^{3}$ Department of Chemistry, Rajshahi University, Rajshahi 6205, Bangladesh
}

Received 12 June 2016, accepted in final revised form 14 August 2016

\begin{abstract}
Radical emulsion polymerization of 1,1-bis(ethoxycarbonyl)-2-vinylcyclopropane (ECVCP) was examined in the presence of potassium persulfate (KPS) as an initiator. ECVCP underwent both emulsifier-in emulsion and emulsifier-free emulsion polymerizations to afford the ring-opened polymer in good yields. The copolymerization efficiency of this monomer was also evaluated with methyl methacrylate (MMA) and butyl methacrylate (BMA) as comonomers under the same reaction conditions. The emulsion copolymerization of ECVCP with a relatively hydrophobic monomer, lauryl methacrylate (LMA) was also investigated in presence of $\beta$-cyclodextrin hydrate $(\beta$-CD) as a phase transfer agent. Polymerization/copolymerization kinetics, change in particle size and olefin contents were followed during the reaction.
\end{abstract}

Keywords: Vinylcyclopropane; Radical polymerization; Kinetics; Particle size and distribution.

(C) 2016 JSR Publications. ISSN: 2070-0237 (Print); 2070-0245 (Online). All rights reserved.

doi: http://dx.doi.org/10.3329/jsr.v8i3.28183 J. Sci. Res. 8 (3), 463-472 (2016)

\section{Introduction}

Vinylcyclopropanes that undergo radical ring-opening polymerization are important in the field of precision materials, dental fillings or adhesives [1], since they show a near zero volume shrinkage or sometimes expansion in volume during their ring-opening polymerization [2]. They undergo radical ring-opening polymerization to give polymers bearing mainly a 1, 5-ring-opened repeat unit, which introduces main-chain unsaturation [3-10] (Scheme 1). Radical polymerization in a dispersion media, particularly emulsion polymerization, is widely used to prepare paints, adhesives, coatings, fibres and construction materials. T. Endo et al. studied the soap-free emulsion copolymerizations of

\footnotetext{
*Corresponding author: p.sarker@ymail.com (P. Sarker) samarhass@yahoo.com (H. Ahmad)
} 
1,1-bis(ethoxycarbonyl)-2-vinylcyclopropane (ECVCP) with vinyl acetate and maleic anhydride in terms of yield and particle size [11]. They obtained only $64 \%$ yield for copolymer with vinyl acetate and copolymerization with acrylonitrile was not successful. Until now radical emulsion copolymerization of ECVCP with vinyl monomers remained a challenge for the researchers and no detail report is available in the area. Meanwhile, it has been observed that unsaturated polymers obtained by emulsion copolymerization of dienes with methacrylates undergo cleavage to form telechelic oligomethacrylates $[12,13]$ and have been found to be suitable as precursors in the synthesis of co-networks that will find applications in cell culture and tissue engineering [14]. Considering this, emulsion copolymerization of ECVCP with acrylate monomers may be interesting as the resulting copolymers are expected to have unsaturated cleavage points.

In this paper, radical ring-opening emulsion polymerization behaviour of ECVCP has been investigated. Additionally, its copolymerizations with methyl methacrylate (MMA), butyl methacrylate (BMA) and lauryl methacrylate (LMA) were also carried out. Polymerization kinetics, particle size and polymer composition were studied. The possible reaction route for the radical initiated ring opening copolymerization with MMA is shown in Scheme 2.

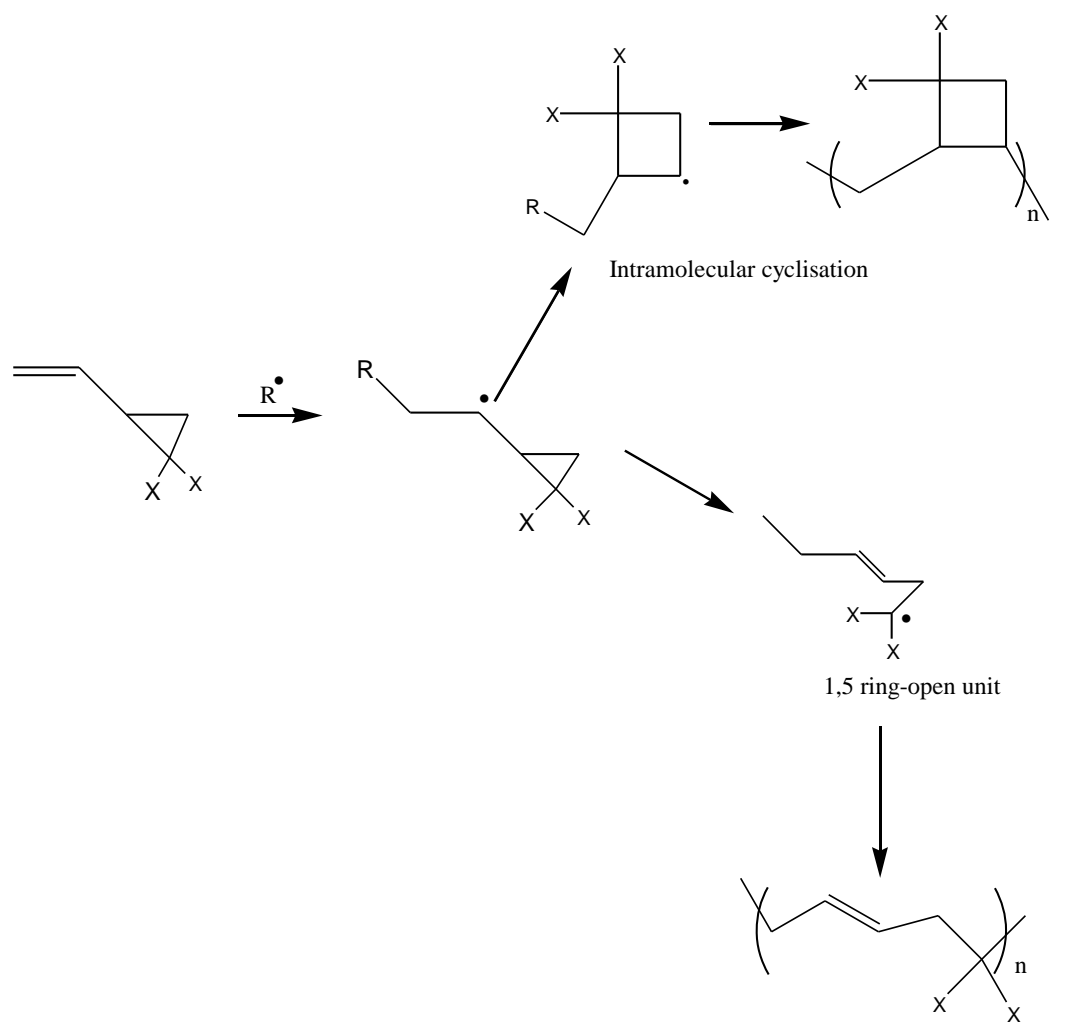

Scheme 1. Radical ring-opening polymerization of ECVCP, where ' $\mathrm{X}$ ' represents $\mathrm{X}=-\mathrm{OCH}_{2} \mathrm{CH}_{3}$, and ' $R$ ' represents the initiator fragments. 


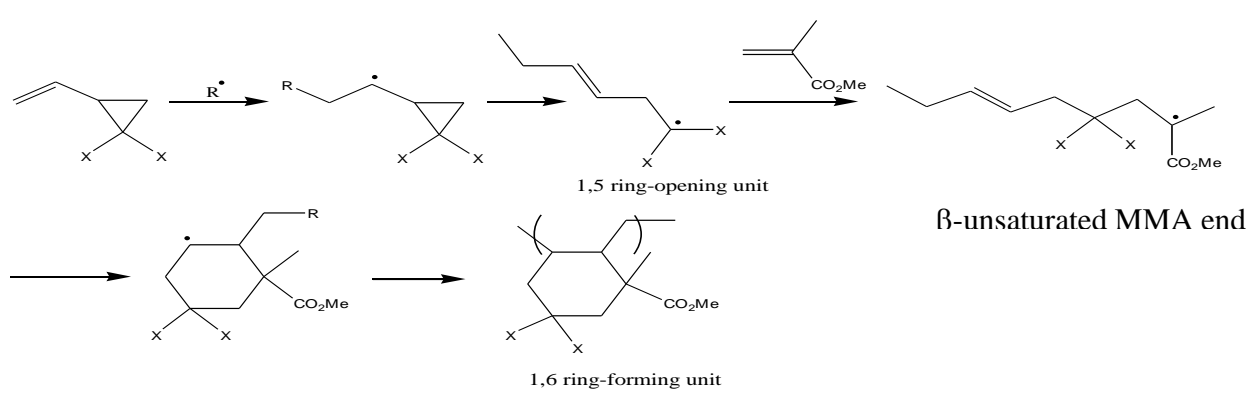

Scheme 2. Copolymerization of ECVCP and MMA, where ' $\mathrm{X}$ ' represents $\mathrm{X}=-\mathrm{OCH}_{2} \mathrm{CH}_{3}$, and ' $\mathrm{R}$ ' represents the initiator fragments

\section{Experimental}

\subsection{Materials}

MMA, BMA and LMA of monomer grade were distilled under reduced pressure and preserved in the refrigerator before use. 1,4-dibromo-2-butene (Aldrich, 99\%), diethyl malonate (Aldrich, 99\%) and sodium hydride (Aldrich, 60\% dispersion in mineral oil) were used as received. Tetrahydrofuran (THF) was refluxed, and distilled from $\mathrm{LiAlH}_{4}$ to remove water, peroxide, inhibitors and other impurities. Chlorobenzene (Aldrich, 99.8\%), potassium persulfate (KPS, Aldrich), sodium lauryl sulfate (SDS, Aldrich), $\beta$-cyclodextrin hydrate $(\beta-\mathrm{CD})($ Aldrich), Dowfax $2 \mathrm{~A} 1$ and potassium hydrogen phosphate were used as received.

Table 1. Characteristics of the polymer/copolymer latexes prepared by emulsion polymerization / copolymerization at $70^{\circ} \mathrm{C}, 8 \mathrm{~h}$.

\begin{tabular}{|c|c|c|c|c|c|c|c|}
\hline $\begin{array}{l}\text { ECVCP }\left(\mathrm{M}_{1}\right) \\
\text { in feed } \\
(\mathrm{mol} \%)\end{array}$ & $\begin{array}{l}\text { Comonomer } \\
\left(\mathrm{M}_{2}\right)\end{array}$ & $\begin{array}{l}\mathrm{M}_{2} \text { in feed } \\
(\mathrm{mol} \%)\end{array}$ & $\begin{array}{l}\text { Yield } \\
(\%)\end{array}$ & $\begin{array}{l}\mathrm{Mn}^{\mathrm{a}} \\
\left(\mathrm{g} \mathrm{mol}^{-1}\right)\end{array}$ & $\mathrm{PD}^{\mathrm{a}}$ & $\begin{array}{l}\text { ECVCP in } \\
\text { copolymer }^{b} \\
(\mathrm{~mol} \%)\end{array}$ & $\begin{array}{l}\text { Olefin content } \\
\text { in copolymer } \\
(\mathrm{mol} \%)\end{array}$ \\
\hline $\begin{array}{l}100 \text { (soap in } \\
\text { emulsion) }\end{array}$ & None & 0.0 & 85 & 39,500 & 3.5 & 100 & 55 \\
\hline $\begin{array}{l}100 \text { (soap free } \\
\text { emulsion) }\end{array}$ & None & 0.0 & 100 & 97,900 & 4.8 & 100 & 58 \\
\hline 50 & MMA & 50 & 56 & 7,850 & 3.1 & 82 & 13 \\
\hline 50 & BMA & 50 & 78 & 2,500 & 4.8 & 46 & 0 \\
\hline$\underline{50}$ & LMA & 50 & 60 & 19,600 & 2.1 & 22 & 2 \\
\hline
\end{tabular}

${ }^{\text {a }}$ Estimated by SEC based on polystyrene standards.

${ }^{\mathrm{b}}$ Determined by ${ }^{1} \mathrm{H}$ NMR.

\subsection{Characterizations}

${ }^{1} \mathrm{H}$ NMR spectra were recorded on Bruker $250 \mathrm{MHz}$ spectrometer operating in the pulsed FT mode in $\mathrm{CDCl}_{3}$ at ambient temperature. Molecular weight and its distribution $\left(\mathrm{M}_{\mathrm{w}} / \mathrm{M}_{\mathrm{n}}\right)$ were evaluated by size exclusion chromatography (SEC) equipped with polymer 
laboratory gel columns, using THF as an eluent, a flow rate of $1.0 \mathrm{ml} / \mathrm{min}$, polystyrene calibration, and a refractive index detector. Particle sizes of all lattices were obtained by Particle Size Analyser, Brookhaven Instruments Corporation. Table 1 summarises the characteristics of the polymer/copolymer latexes prepared at $70^{\circ} \mathrm{C}$.

\subsection{Synthesis of 1,1-bis(ethoxycarbonyl)-2-vinylcyclopropane (ECVCP)}

A solution of 1,4-dibromo-2-butene $(12.84 \mathrm{~g}, 0.06 \mathrm{~mol})$ and diethyl malonate $(7.5 \mathrm{~g}, 0.06$ $\mathrm{mol})$ in THF $(50 \mathrm{~mL})$ was added drop-wise into THF $(200 \mathrm{~mL})$ containing sodium hydride $(2.8 \mathrm{~g}, 0.12 \mathrm{~mol})$ at room temperature [8]. After the addition, the reaction mixture was refluxed at $70^{\circ} \mathrm{C}$ over-night. The resulting mass was filtered off and washed with ethanol twice. The combined filtrate was evaporated, and the residue was distilled under reduced pressure $\left(65^{\circ} \mathrm{C} / 4 \mathrm{mmHg}\right)$.

The product was characterised by ${ }^{1} \mathrm{H}$ and ${ }^{13} \mathrm{C}$ NMR, elemental analysis and GC-MS. Yield: $18.5 \mathrm{~g}(90 \%)$, purity: $100 \%$ (by GC and TLC). ${ }^{1} \mathrm{H}$ NMR: $\delta 1.30(\mathrm{t}, 6 \mathrm{H}), 1.48-1.54$ (m, 2H), 2.4-2.53 (m, 1H), 4.25 (q, 4H), 5.15-5.52 (m, 3H).

Elemental analysis: Calc. C62.26\%, H7.55\%; Found C62.57\%, H7.75\%; GC-MS: GC Ret. Time, 9.02 and MS MH', $213\left(\mathrm{NH}_{3}\right)$.

\subsection{Emulsion polymerization of (ECVCP) and its copolymerization with $M M A / B M A / L M A$}

Emulsion polymerization of ECVCP was performed in a batch reactor equipped with a mechanical stirrer, nitrogen inlet and thermal probe. A mixture of ECVCP (10 g), deionised water $(100 \mathrm{~g})$ and $\operatorname{SDS}(0.5 \mathrm{wt} \%$ based on total monomer), for soap-in emulsion only was stirred at $400 \mathrm{rpm}$. The mixture was heated up at $70^{\circ} \mathrm{C}$ and initiator KPS ( $1 \mathrm{wt} \%, 0.1 \mathrm{~g}$ ) was added into the reaction mixture. For emulsion copolymerization, MMA (2.3584 g, $0.0235 \mathrm{~mol})$, BMA (3.35 g, $0.0235 \mathrm{~mol})$ and LMA (5.9 g, $0.0235 \mathrm{~mol})$ were used, as comonomer respectively. In each copolymerization $5 \mathrm{~g}(0.0235 \mathrm{~mol})$ of ECVCP was used. Emulsifiers, 5 wt \% SDS based on total monomer was used in ECVCPMMA and ECVCP-BMA copolymerzation systems whereas 5 wt \% dowfax 2A1 was used in ECVCP-LMA copolymerization system. The polymer samples were collected at different time intervals, immediately quenched and the monomer conversion was measured by a gas chromatography. The overall conversion was measured gravimetrically.

Fig. 1 shows time-conversion plot for the radical emulsion polymerization of ECVCP. Compared with emulsifier-free emulsion polymerization, the presence of SDS facilitates the participation of ECVCP in the reaction at lower conversion and consequently results in higher conversion rate until $78 \%$ conversion. The increase in conversion rate in presence of emulsifier is very typical behavior for emulsion polymerization as long as the rate of initiation is high enough to supply sufficient radicals for the increasing number of particles [15]. The average particle size of poly-ECVCP latex 
prepared in absence of SDS $(105 \mathrm{~nm})$ was slightly higher than that prepared in presence of $0.5 \mathrm{wt} \%$ SDS $(95 \mathrm{~nm})$. This implies that the presence of even small amount of SDS allows stabilization of higher particle surface area at a given conversion and hence higher particle numbers. Interestingly, the number average molecular weight $\left(M_{n}\right)$ of ECVCP polymer chain obtained in emulsifier-free system was much higher than that obtained in presence of emulsifier (Table 1). In other word propagation reaction dominates over termination in the emulsifier-free system. The presence of emulsifier increases solubilisation of monomers and hence the formation of oligoradicals in the aqueous phase, some of which may undergo bimolecular termination before being captured by the growing particle. Bimolecular termination within the particle as well as relatively higher number of particle centres also contributes for this lower molecular weight.

\section{Results and discussion}

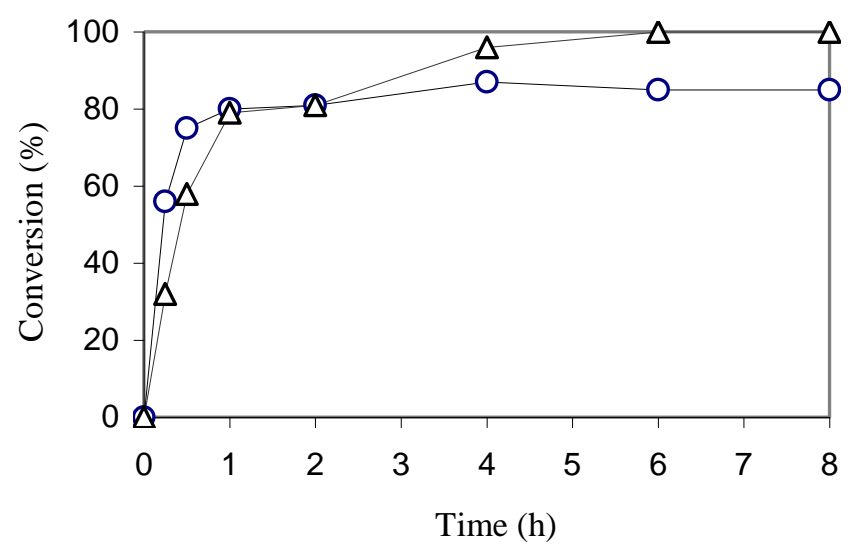

Fig. 1. Time-conversion curve for radical emulsion polymerization of ECVCP carried out in presence of $0.5 \mathrm{wt} \% \operatorname{SDS}(\mathrm{o})$ based on monomer and in absence of SDS $(\Delta)$.

The copolymerization efficiency of ECVCP was evaluated by carrying out emulsion copolymerization with MMA, BMA and LMA, respectively. The copolymerization reactions with MMA and BMA were carried out in presence of $5 \mathrm{wt} \%$ SDS based on total monomer whereas that with LMA was carried out in presence of 5 wt $\%$ dowfax 2A1 also based on total monomer. The molar ratio of the ECVCP / comonomer was fixed at the same level (1/1) in each copolymerisation system. $\beta$-CD was used as a phase transfer agent for copolymerisation with hydrophobic LMA. The conversion of the individual monomer was monitored by GC and the overall conversion was obtained gravimetrically. The results are shown in Fig. 2a-c. In all three copolymerization systems ECVCP enters the polymer chain slower than the comonomer. This is possibly attributed to the difference in monomer reactivity ratio and the complex initiation step involved with ECVCP monomer (Scheme 2). The appearance of the conversion curves suggests that 
poly(ECVCP-MMA) chain is likely to have comparatively uniform composition as the conversion curves of MMA and ECVCP are close to each other. In each copolymerisation system the overall final conversion is relatively low as compared to the conventional free radical copolymerisation of vinyl monomers in the aqueous media [16]. It is to be mentioned that in absence of emulsifier the conversion (data not shown) was very low which again indicates that the presence of emulsifier increases the participation of ECVCP and respective comonomer in the copolymerisation reaction.
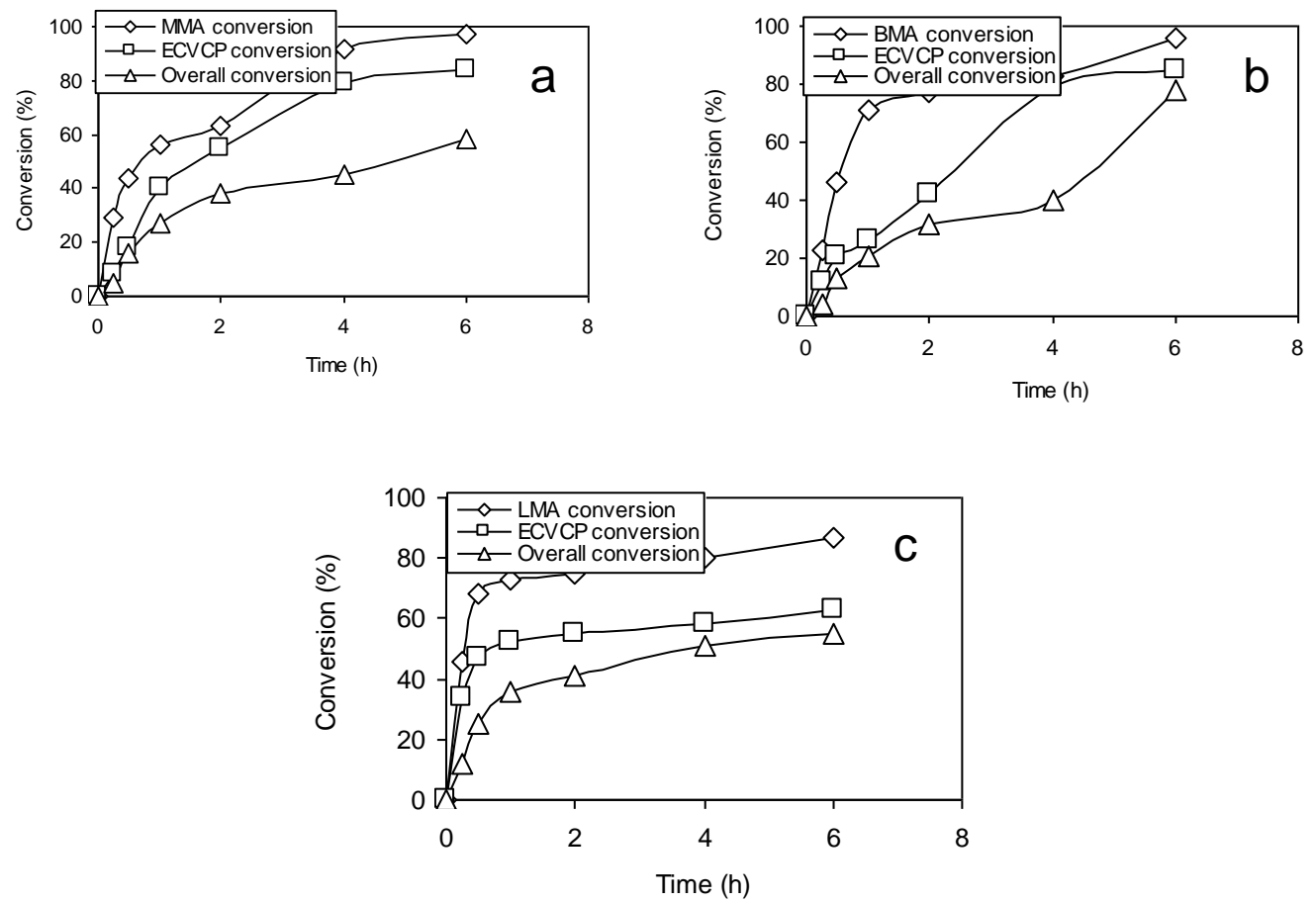

Fig. 2. Time-conversion curves for radical emulsion copolymerization of ECVCP with a) MMA, b) BMA, and c) LMA in presence of 5 wt \% SDS (a, b) and 5 wt \% dowfax 2A1 (c). The comonomer content $(0.0235 \mathrm{~mol})$ was kept identical with the ECVCP monomer.

The average particle sizes measured at different time intervals during the copolymerization of ECVCP with MMA, BMA and LMA are presented in Fig. 3. In copolymerization reactions with MMA and BMA the particle size increases with the progress of the reaction which is commonly observed in most emulsion systems. However, with LMA the particle size gradually decreases after a slight initial increase. Prolonged nucleation period effected by the poor solubility of hydrophobic LMA [17,18] may be responsible for this gradual decrease until the middle of the reaction. The sharp increase in particle size towards the end indicates the possibility of partial coagulation of large number of nucleated particles formed along the copolymerization reaction. The composition of monomer mixture has also a strong influence on the average particle size 
with less hydrophobic MMA has the minimum value. It is obvious that persulfate radicals derived from potassium persulfate (KPS) initiator start polymerization of the monomers dissolved in the aqueous phase with the formation of oligoradicals. The presence of comparatively less hydrophobic MMA in the monomer mixture is therefore expected to increase the formation of oligoradicals and hence to some extent produces more primary particles. The greater the number of primary particles form the lower is the average particle size [19]. The total monomer content has also some effects on the average particle size as the monomer composition has been used was based on molar ratio rather than on weight ratio.

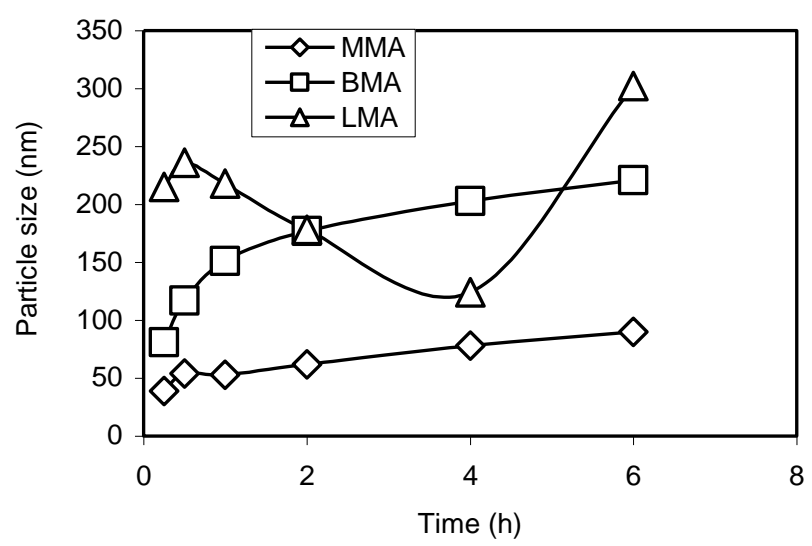

Fig. 3. Change in the average particle size of the copolymer latexes during the course of copolymerization obtained in presence of different comonomers in the recipe.

The structures of the homo- and co-polymers were examined by ${ }^{1} \mathrm{H}$ NMR spectra. Fig. 4a-d shows the spectra of the final homo- and co-polymer latexes dissolved in $\mathrm{CDCl}_{3}$. The composition of the copolymer was calculated from the ratio of the peak areas of the methylene protons $(\delta 4.25 \mathrm{ppm})$ of the ester group derived from ECVCP to that of the methyl protons (3.65 ppm) of the ester group derived from MMA, BMA and LMA (Fig. 4 b-d). The calculated results are summarized in Table 1. The radical ring-opening polymerization of ECVCP produces polymer containing olefin groups in the main chain due to the presence of 1, 5 ring-opened units. In the spectra of (ECVCP-MMA) and (ECVCP-LMA) copolymer latexes, olefinic signals $(5.35 \mathrm{ppm})$ due to the 1,5 ringopened unit (Figs. 4b \& d) are observed but in the spectrum of (ECVCP-BMA) copolymer latex no such signal is observed. It is to be mentioned that for measuring the olefin content, area of $1 \mathrm{H}$ from olefin (double bond) and area of $1 \mathrm{H}$ proton from $\mathrm{CH}_{3}$ derived from MMA was used. In contrast, $\mathrm{CH}_{2}$ signal was used for LMA due to overlapping. LMA has eleven $\mathrm{CH}_{2}$ and MMA has one $\mathrm{CH}_{3}$ only. That's why \% of olefin content gone down for LMA. Also, the methoxy groups of the MMA and ECVCP residue gave coincident resonances $(\delta 4.15 \mathrm{ppm})$. The spectra derived from copolymerization with 
BMA or LMA clearly shows two separate methyleneoxy peaks at $\delta 3.95 \mathrm{ppm}$ and $\delta 4.15$ ppm, respectively.
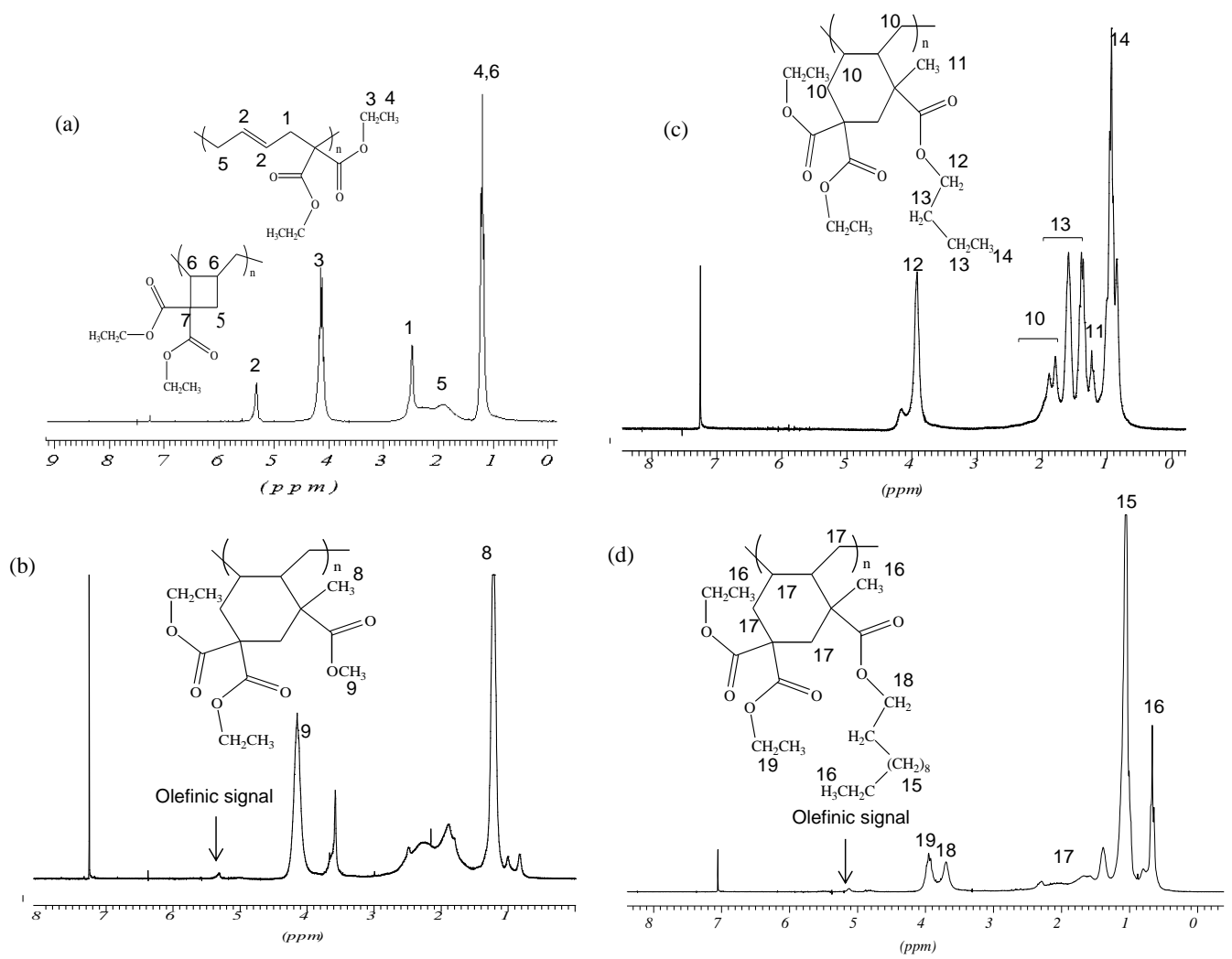

Fig. 4. ${ }^{1} \mathrm{H}$ NMR spectra of polymers (solvent $\mathrm{CDCl}_{3}, 250 \mathrm{MHz}$ ): (a) poly(ECVCP), (b) poly (ECVCP-MMA), (c) poly(ECVCP-BMA), and (d) poly(ECVCP-LMA).

Fig. 5 shows how the fraction of double bonds changes during the copolymerization reaction as the comonomer is changed. There is a substantial decrease in the fraction of ECVCP repeat units that contain double bonds in the copolymers compared to the homo poly(ECVCP) and in each case the double bond content decreases over time. The time dependant decrease is a result of copolymerization of the unsaturated main chain alkenes and particularly in the copolymerizations with MMA, BMA and LMA give rise to polymodal or broad molecular weight distributions. The copolymer chain produced by the copolymerization with MMA contains relatively more olefins (also see Table 1). 


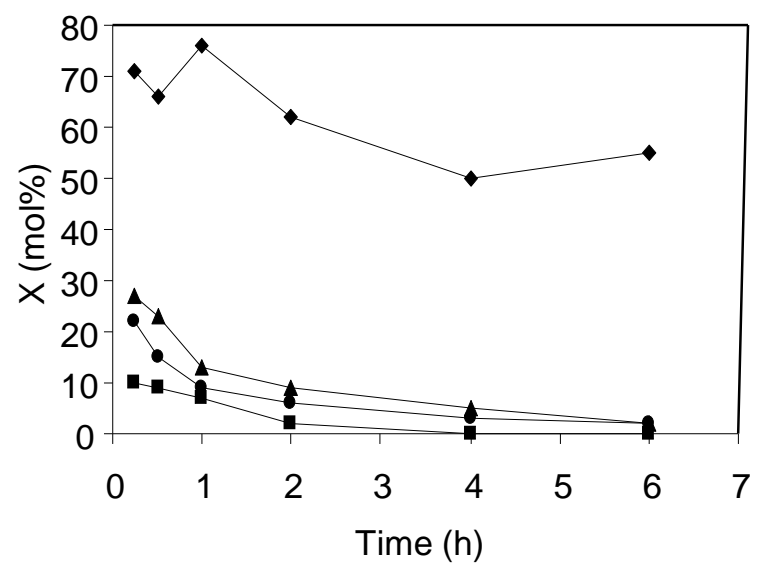

Fig. 5. Change in olefin contents during the course of homopolymerization of ECVCP ( $\downarrow)$ and

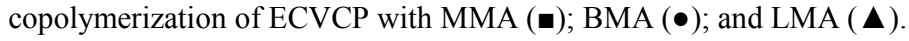

\section{Conclusion}

ECVCP can be radically homopolymerized in the emulsion system both in absence and presence of anionic SDS emulsifier. Presence of emulsifier produced rather low molecular weight ECVCP polymer chain. Emulsion copolymerizations of ECVCP with acrylate monomers such as MMA, BMA and LMA are also possible with fairly good conversion but the inclusion of the comonomer units greatly influenced the configuration of ECVCP units in copolymer chain.

\section{References}

1. R. M. Russel and R. K. Sadhir, Expanding Monomers-Synthesis, Characterisation and Application (CRC Press, Boca Raton, 1992) pp. 2.

2. F. Zeuner, N. Moszner, and V. Rheinberger, Macromol. Chem. Phys. 197, 2745 (1996). http://dx.doi.org/10.1002/macp.1996.021970912

3. T. Takahashi, J. Polym. Sci. Polym. Chem. Ed. 6, 403 (1968). http://dx.doi.org/10.1002/pol.1968.150060210

4. T. Endo, M. Watanabe, K. Suga, and T. Yokazawa, J. Polym. Sci. Polym. Chem. Ed. 25, 3039 (1987). http://dx.doi.org/10.1002/pola.1987.080251109

5. T. Endo and K. Suga, J. Polym. Sci. Polym. Chem. Ed. 27, 1831 (1989). http://dx.doi.org/10.1002/pola.1989.080270604

6. T. Endo, M. Watanabe, K. Suga, and T. Yokazawa, Macromol. Chem. 190, 691 (1989). http://dx.doi.org/10.1002/macp.1989.021900402

7. F. Sanda, T. Takata, and T. Endo, Macromolecules 25, 6719 (1992). http://dx.doi.org/10.1021/ma00050a053

8. F. Sanda, T. Takata, and T. Endo, Macromolecules 26, 1818 (1993). http://dx.doi.org/10.1021/ma00056a027

9. F. Sanda, T. Takata, and T. Endo, Macromolecules 28, 1346 (1995). http://dx.doi.org/10.1021/ma00124a029 
10. J. Sugiyama, K. Ohashi, and M. Ueda, Macromolecules 27, 5543 (1994). http://dx.doi.org/10.1021/ma00086a001

11. F. Sanda, Y. Takamatsu, F. Hoshino, and T. Endo, J. Appl. Polym. Sci. 68, 497 (1998). http://dx.doi.org/10.1002/(SICI)1097-4628(19980418)68:3<497::AID-APP15>3.0.CO;2-S

12. T. Hirano, A. Tabuchi, M. Seno, and T. Sato, Macromolecules 34, 4737 (2001). http://dx.doi.org/10.1021/ma001962t

13. J. R. Ebdon and S. Rimmer, J. Polym. Sci. Polym. Chem. Ed. 35, 3255 (1997). http://dx.doi.org/10.1002/(SICI)1099-0518(19971115)35:15<3255::AID-POLA19>3.3.CO;2-K

14. D. Cunliffe, J. E. Lockley, J. R. Ebdon, S. Rimmer, and B. J. Tabner, Macromolecules 34, 3882 (2001). http://dx.doi.org/10.1021/ma001313h

15. K. Tauer, The Role of Emulsifiers in the Kinetics and Mechanisms of Emulsion Polymerization, In: Applied Surfactant Series; D. R. Karsa, (eds.) (Blackwell Publishing, CRC Press: Oxford, UK, 2003) 1, pp. 32.

16. H. Ahmad, A. H. M. T. Islam, M. A. Hossain, M. A. J. Miah, and K. Tauer, e-Polymers 6, 388 (2006).

17. H. Ahmad, M. K. Hasan, M. A. J. Miah, A. M. I. Ali, and K. Tauer, Polymer 52, 3925 (2011). http://dx.doi.org/10.1016/j.polymer.2011.07.004

18. R. Shabnam, A. M. I. Ali, M. A. J. Miah, K. Tauer, and H. Ahmad, Colloid Polym. Sci. 291, 2111 (2013). http://dx.doi.org/10.1007/s00396-013-2952-7

19. H. Ahmad, M. E. Hossain, M. A. Rahman, M. M. Rahman, M. A. J. Miah, and K. Tauer, e-Polymers, 8, 1109 (2008). 